\title{
Determinants of customers' loyalty for hospitality industry
}

\author{
*Sher Akbar'1, Ahmad Puad Mat Som² \\ 1,2School of Housing, Building and Planning,University Sains Malaysia, Pulau, Pinang, Malaysia \\ *sherakbar.rd07@student.usm.my
}

\begin{abstract}
Customer loyalty is very necessary for the competitive market environment. The growing presence of relationship marketing efforts has led to increased competition among service providers. So hospitality industry is more service oriented, effecting by customers' interest. To achieve the desirable customer to the business, for this purpose Relationship marketing efforts would have to be implemented in order to determine whether frequent guest is loyal to the particular company. Previous research has identified the determinants of customers' loyalty for a hotel industry and has been adapted and used in this study. Structural equation analysis was applied to identify which factors (service quality, customer satisfaction, trust, value and hotel membership program, socio demography of the customer) have positively impact customer loyalty. According the result of this study all the determinants of loyalty have significance relationship with customer loyalty, and it was also indentified that customer loyalty as a function of both behavioral and attitudinal loyalty. The framework adopted and modified for this research demonstrated the formation of a solid structure that would allow for collecting valuable findings. This study has extended and adopts the previous loyalty model and has been applied in the hotel industry of Penang, Malaysia.
\end{abstract}

Keywords: Determinants of Customer Loyalty, Hotel Industry, Penang, Malaysia

\section{Introduction}

As an hotelier in the industry, it is important to offer products or services that enable sustainability in the industry. If not, the ability to derive necessary market share may be jeopardized. At the same time, it is important to be knowledgeable of the customers who patronize your hotel(s). Knowing their needs and demands and utilizing this information for product or service implementation purposes. It will go a long way towards long-term sustainability and loyalty creation efforts. It is also important to give considerable attention to the efficiency of the facilities and services provided. Customers expected service to be delivered in an expedient manner. Gold (2005) validates this inherent belief and also discusses how instant gratification and convenience are important from the customers' perspective. Despite the growth, the Malaysian hotel industry is facing a lot of challenges due to external and internal factors in its business environment. The external factors include solid competition from peers and uncertainties in the hospitality industry. For example, it was reported, that the impact of uncertainties due to Severe Acute Respiratory Syndrome (SARS) and terrorists attacks on the industry. These external factors have severely affected the Malaysian tourism industry particularly the hotel industry (Malaysian Association of Hotel (MAH), 2004). Besides the external factors, hotels have to deal with internal challenges which are related to hotel management. This internal factor may contribute to their poor performance in terms of low level of service quality (Lau, et al 2005). The importance of managing customer requirement is acknowledged by hotel industry as the general managers place customer retention as the top priority strategy (Teare \& Bownen, 1997). In order to manage customer requirement and improve hotel performance, the customer loyalty is very important, which may influence the hotel industry overall performance. Through the assessment of guests' perspectives, the researcher intends to derive the importance of gathering this pertinent information. This assessment will also contribute to the advancement of hospitality research and provide a newfound viewpoint on how loyalty is vital for five star hotels. It is important to note that testing whether the findings of this study derived from the five star hotel segments are consistent with those of other hotel segments (i.e. economy, mid-price, and luxury) remains an important topic to explore for future researchers. The objective of this study is to examine which antecedents (i.e. perceived quality, trust, satisfaction, perceived value, sociodemography, and hotel membership programs) have significant effect(s) on guest loyalty. 


\section{Literature Review}

The growing presence of relationship marketing efforts has led to increased competition amongst hotels; they focus on the development of loyalty programs to be offered to guests. Hospitality corporations began realizing that greater and more strategic efforts are necessary. Furthermore, relationship marketing efforts would have to be implemented in order to determine whether frequent guests are loyal to either the brand or the company. Taylor et al (2004) assessed the importance of brand equity as it related to customer loyalty. There are different determents effecting customers' loyalty, but the most common are customers satisfaction, service quality and value, resistance to change, brand affect, trust, and brand equity as predictors of customers' perceptions of loyalty. By using structural equation analysis, the researchers identified customer loyalty as a function of both behavioral and attitudinal loyalty. This approach was taken in response to a valid proposition and supportive findings that were made by White and Schneider (2000). Baloglu (2002) also incorporated attitudinal and behavioral loyalty into customer loyalty dimensions. His reasoning was conceptual and practical. Studies have demonstrated that customer loyalty is a multi-dimensional concept and that it involves both behavioral and attitudinal elements. According to Taylor et al (2004), Service quality is the major reference in measuring customers' loyalty. The framework developed in their research demonstrated the formation of a solid structure would allow for collecting invaluable findings. This study will extend and adapt the previous loyalty model. A lack of concentration in this area can result in detrimental effects on efforts to maintain and increase the level of loyalty. It was also shown that satisfaction has a direct influence on customer loyalty However; his research focus was directed towards measuring hotels' responses to customer complaints. Skogland and Siguaw (2004) measured the degree to which satisfaction influenced loyalty. These two particular researchers felt the degree to which the customer was involved in the purchase decision had a strong effect on the propensity to switch service providers. They measured this impact by using the confirmation-disconfirmation and comparison-level theories. The satisfaction antecedents used included service quality, product quality, price, and location. They felt this construct, along with the measurement of satisfactions affect on involvement, all culminated to assess the overall impact of satisfaction on loyalty.

Many researchers have highlighted the proposed determinants of customers' loyalty; some of them are discussed here. Antony and Ghosh (2004) believed service quality to be so intangible that objective measurement is impossible. The researchers believed the challenges laid mostly in managing appearances and perceptions. McCain et al (2005) discussed service quality plays an important role in the assessment of customer loyalty. Antony and Ghosh (2004) also stated service quality as being linked to customer satisfaction and customer loyalty. The researchers measured this impact by looking at tangible and intangible elements of service through technical and functional quality. In the realm of perceived value, an excerpt written by Brady and Cronin (2001) stated, "Customers' value perceptions seem to drive their future behaviors such as repurchase intent and word-of-mouth referrals." Bojanic (1996) asserted that a firm's value can be changed once the firm change the way they are doing. If a competitor wants to get more customers, it is necessary to bring their service to the customers' needs and preference. Baloglu (2002) endeavored to separate "friends" from "well wishers." This researcher focused on determining whether frequent guests were truly loyal by assessing both guests' attitudes and their actions. He classified the "dimensions of customer loyalty" as being low, latent, spurious, and true loyalty. In terms of effectiveness, Lal and Bell (2003) alluded to the fact that few studies shed light on the return obtained from loyalty programs. It is very important to measure guests' perspective on the usage and their dependence on membership programs. The findings from this inquiry can provide very important information as it regards hotel's consideration of continued investment in its offering of a membership program. The above mentioned studies were mostly theoretical. To find the empirical evidence, this study was conducted to investigate how these determinants affect customer loyalty in the hotel premise.

\section{Methods}

The study has designed using quantitative research methods. Data have been obtained from hotels customers experience about perceived Service quality, satisfaction, and loyalty. Survey research has designed where a multiple regression methods has been used to explore the relationship among the determinants factors and 
customer loyalty. Independent Variable customers and dependent variables are the determinants of loyalty, have measured by the (Taylor et al 2004) instrument, adapted and modified by the researcher. To determine the study's target population is customer of five star hotels in the Malaysian hotel industry, focus area was Penang five star hotels. the study reliability and validity have confirmed through a pilot study. Sample Size, for the preliminary result of this study was 300 respondents. Self administrated questionnaires were distributed. The entire respondents were the five star hotels customers, who stay overnight to that particular five star hotels at Penang Malaysia. The instrument consisted of three sections. At the outset, the respondents were asked to select the hotel name which they are staying in or currently leave the hotel. The first section of the instrument Guests were asked to respond based on a five-point, Likert- type scale anchored from 1 (strongly disagree) to 5 (strongly agree). This section of the survey instrument was comprised of 32 survey questions. These questions represented the determinants of this study (perceived quality, trust, satisfaction, perceived value, and membership program) that would be used to measure impact on guest loyalty. The second section of the survey instrument was comprised of questions relating to guest loyalty. There were eight questions in this section and each allowed guests to respond as they did in section I of the survey instrument using the five-point, Likert-type scale. The third section of the instrument consisted of demographic and socioeconomic status of the customers, some of the questions gathered primarily from Suh (1997).

\section{Finding and Discussion}

Based on the results, it was found that majority of the respondents (32.54\%) were between 36-45 years of age. The results also indicated that 181 respondents $(60.33 \%)$ were males and that 119 respondents (39.66\%) were females. Marital status indicates that 94 (31.33\%) respondents were married and most of the respondent 118 (39.33\%) were from Asia. Descriptive statistical analysis of "income" showed that 25.66\% of the respondents have their annual household incame between, 50,001-65,000 US dollars. Results further indicated that education level of $31.66 \%$ were master degree holder. The majority respondents declare their visit for leisure purpose that was around $46.66 \%$ of the total respondents. The rest $30.00 \%$ were business and $23.33 \%$ were visited to friends and relatives. The detail has shown in the table number 1.

\section{Table 1: Demographical Characteristic of the respondents}

\begin{tabular}{lcc}
\hline Variables & Frequency & Percentage \\
\hline Gender & 181 & \\
Male & 119 & 60.33 \\
Female & & 39.66 \\
Age & 30 & \\
$18-25$ & 58 & 10.00 \\
$26-35$ & 95 & 19.33 \\
$36-45$ & 36 & 31.66 \\
$46-55$ & 57 & 12.00 \\
$56-65$ & 24 & 19.00 \\
Above 65 & & 8.00 \\
Marital Status & 59 & \\
Single/ Never married & 94 & 19.66 \\
Married & 65 & 31.33 \\
Separated & 42 & 16.36 \\
Divorced & 40 & 21.66 \\
Widowed & & 13.33 \\
Your continent & 118 & \\
Asia & 67 & 39.33 \\
Europe & 43 & 22.33 \\
Australia/New Zealand & 33 & 14.33 \\
North America & & 11.00 \\
\hline
\end{tabular}




\begin{tabular}{lrc}
\hline Africa & 24 & 8.00 \\
South America & 15 & 5.00 \\
Annual house hold Income (US dollar) & & 10.66 \\
Less than 35,000 & 32 & 21.00 \\
$35,000-50,000$ & 63 & 5.66 \\
$50,0001-65,000$ & 77 & 19.66 \\
$65,001-80,000$ & 59 & 14.00 \\
$80,001-100,000$ & 42 & 9.00 \\
More then 100,000 & 27 & \\
Education Level & & 11.66 \\
High School certificate & 35 & 15.00 \\
Diploma & 45 & 21.66 \\
Bachelor Degree & 65 & 31.66 \\
Master & 95 & 20.00 \\
PhD & 60 & \\
Main Purpose of visit to Penang & & 30.00 \\
Business & 90 & 46.66 \\
Leisure & 140 & 23.33 \\
Visiting friend \& relative & 70 & \\
\hline
\end{tabular}

Table 2: Factor Analysis (Varimax Rotated Loading)

Varimax Rotated Loading

$\begin{array}{llllll}\text { Factor and Variable } & \text { Factor } 1 & \text { Factor } 2 & \text { Factor } 3 & \text { Factor } 4 & \text { Factor } 5\end{array}$

\section{Perceived Quality}

The appearance of the hotel was excellent .92

Overall room service was excellent $\quad .91$

Overall restaurant service was excellent .89

Perceived Value

This hotel provided me with individual attention $\quad .89$

This hotel operating hours convenient to me. $\quad .79$

This hotel modern equipment $\quad .87$

\section{Satisfaction}

Service renderings met highest expectation $\quad .85$

I am satisfied by my decision to stay in this hotel $\quad .90$

I enjoyed staying in this hotel $\quad .88$

\section{Trust}

I trust the hotel and its staff $\quad .88$

The hotel provides service as promised $\quad .78$

I feel safe in my dealing with the hotel employees. $\quad .80$

\section{Membership Program}

$\begin{array}{ll}\text { I have received discounted room rate by having membership } & .98\end{array}$

Free transport service of the hotel by having membership .88

I have received promotional offers regularly from this hotel .89

\begin{tabular}{lcccccc} 
\% of Variance explained & 17.23 & 13.09 & 12.70 & 11.99 & 11.98 & 66.90 \\
Cronbanch's Alpha & .90 & .74 & .69 & .68 & .68 & \\
Eigenvalue & 3.69 & 2.14 & 1.66 & 1.35 & 1.19 & \\
\hline
\end{tabular}


Note: Kaiser-Meyer-Olkin (KMO) Measure of sampling adequacy (MSA): 0.81

Bartlett's Test of Sphericity" $x^{2}=1294.41$, Significance at $p=.000$

To determine the appropriateness of the data to be used for factor analysis, an investigation was made to decipher whether the determinants possessed any correlation between each other and to also ensure that the attributes were grouped with the appropriate determinants. For the purpose of this analysis, Principal Component Analysis was used to discover or reduce the dimensionality of the data set. Varimax rotation, a method of orthogonal rotation that centers on simplifying the factor matrix by maximizing variance and producing conceptually pure factors, was applied with Kaiser Normalization to extract attributes and/or determinants not significance to this study. To be valued as significant, each attribute must have loading cutoff value of .50 or greater. Only factors with an Eigen value of $>1$ were considered as significant. It was revealed during this form of analysis that respondents perceive "The overall tangible and intangible elements of service for the hotel's food and beverage outlets (i.e. restaurant, room service) were excellent" to be of the same regard as the other two questions relating to "perceived quality" (.91) Respondents also favor the question "I trust the hotel and its staff" to be of the same nature of context as the two other questions representing. "Trust" (.88) as mentioned earlier, "membership program" responses was of great favor. Two particular questions well-regarded were "I received discount rate by having membership of the hotel (.88) and "I have received promotional offer regularly." (.98). Overall, the determinants of loyalty have reached to significant level of acceptance.

\section{Regression Analysis}

Based on the findings illustrated in table 3 with regard to the study's determinants and attitudinal loyalty, the coefficient of the determinant (R2) was 27 and the adjusted R2 was .26. As it regarded attitudinal loyalty, the F-ratio value was $26.96(\mathrm{p}<.01)$, indicating that the results of this regression model could hardly have occurred by chance. In order to assess the relative importance, beta coefficients were used: the higher the beta coefficients, the more important each determinant. It is important to note that all five turned out to be statistically significant $(\mathrm{p}<.01)$ antecedents influencing attitudinal loyalty. The most important determinant affecting guest attitudinal loyalty was found to be "satisfaction" with a beta value of .26 followed by "trust" with .27 , and "membership program" with .22. Perceived value with a beta value of .11 was found to be the least important determinant affecting guest attitudinal loyalty and perceived quality with .20 was the second least important one. Five star hotel guests perceive "satisfaction" to be of highest importance and "perceived" value to be least important, based on beta value and significance level. To detect multicollinearity, variance influential factor (VIF) testing was conducted. No serious multi-collinearity is present with respect to the determinants against attitudinal loyalty components, since a variation inflation factor (VIF) of 1 is much smaller than the threshold value of 10 (Hair et al., 1995). It can be concluded that, in descending order, trust, satisfaction, membership program, perceived quality, and perceived value were found to be significant determinants of attitudinal loyalty.

Table 3: Regression of Attitudinal Loyalty

\begin{tabular}{lccccc}
\hline \multicolumn{1}{l}{ Independent Variable } & $\mathbf{b}$ & Beta & $\mathbf{t}$ & Sig. & VIF \\
\hline Constant & .04 & & & & \\
Satisfaction & .25 & .26 & 6.24 & 0.000 & 1.00 \\
Trust & .21 & .27 & 5.12 & 0.000 & 1.00 \\
Membership program & .20 & .22 & 4.20 & 0.000 & 1.00 \\
Perceived Quality & .18 & .20 & 3.11 & 0.000 & 1.00 \\
Perceived Value & .11 & .11 & 2.10 & 0.002 & 1.00 \\
\hline
\end{tabular}

$\mathrm{R} .=.55, \mathbb{R}^{2}=.27$, adjusted $R^{2}=.26, \mathrm{~F}=26.96, \mathrm{p}<.01$ 
Based on these findings, there is an indication of greater variability when it comes to guest behavioral considerations of loyalty versus attitudinal considerations. This is in consideration of the distribution of "beta" and "t-value" responses, as well as from assessment of the "F-statistic" value. There is an indication to affirm, based on the responses, that these determinants play a major role when it comes to guest loyalty towards five star hotels. It is believed that major consideration is placed on efforts to ensure effectiveness in delivering services that would encompass guests' measurement of this particular construct. Lastly, it is important to note, based on VIF, that no sign of multicollinearity is existent with respect to the determinants and their impact upon behavioral loyalty.

Table 4: Regression of Behavioral Loyalty

\begin{tabular}{lccccc}
\hline Independent Variable & $\mathbf{b}$ & Beta & $\mathbf{t}$ & Sig. & VIF \\
\hline Constant & .02 & & & & \\
Satisfaction & .26 & .22 & 6.34 & 0.000 & 1.00 \\
Trust & .24 & .23 & 5.34 & 0.000 & 1.00 \\
Membership program & .19 & .20 & 5.20 & 0.000 & 1.00 \\
Perceived Quality & .17 & .18 & 4.11 & 0.000 & 1.00 \\
Perceived Value & .11 & .11 & 3.10 & 0.000 & 1.00 \\
\hline
\end{tabular}

$\mathrm{R}=.73, R^{2}=.56$, adjusted $R^{2}=.52, \mathrm{~F}=65.15, \mathrm{p}<.01$

\section{Conclusion and Recommendations}

Among the determinants and their relationship against attitudinal and behavioral loyalty, "satisfaction" was consistently valued the most, followed by "trust." Disparity, however, becomes apparent when it comes to the remaining determinants (perceived quality, perceived value, and membership program). The attitudinal loyalty measurement regarded "membership program" as its third most valued while the behavioral loyalty positioned "perceived quality" as its third. Results for the fourth most valued determinant, indicated "perceived quality" from the attitudinal loyalty measurement, while "perceived value" was behavioral loyalty's fourth most valued. The results from this study were found to comparably reflect the findings of notable researchers such as Taylor et al (2004) as they found that "brand equity" and "trust" consistently appeared to be most influential in fostering both behavioral and attitudinal loyalty. The same was the case with Baloglu (2002) as his study found that its "truly loyal" customers had more trust and emotional commitment to the service quality than either of the other loyalty groups. It is based on the cross-comparison of these two findings that demonstrate how this particular study's findings are somewhat similar in terms of classifying "trust" as an important determinant of guest loyalty. It is important to note, however, that as was alluded from this study, "satisfaction" was found to be most valued by guests of five star hotels. This is due to characteristics of the hotel industry. Unlike most industries, specifically the manufactured industry, the hotel industry has evolved to the point that guests have greater options by which to choose their accommodation needs. With the number of hotels being developed, this will continue to be prevalent within the industry. It is very apparent that "satisfaction" is regarded as the salient dimension affecting customer loyalty among guests who patronize five star hotels. In other industries, as research indicates, "trust" has been prescribed as the determinant that affects customer loyalty. With the current state of the hospitality industry, this disparity serves as an important factor in the pressing matter of guest loyalty. This pilot study has shown that all the determinants were significant for loyalty, and provided a platform for further research in other areas in the hotel industry.

Based on this study finding, it would be a great contribution to hospitality education, that a research can be conducted on adapting this loyalty measurement to other hotel segments. Hoteliers of other hotel segments are experiencing the same challenge and this assessment would be of great benefit. It would also be of great benefit for five star hoteliers to develop a study to reflect loyalty as it related to customers perception of marketing and advertisement efforts. This would enable the ability to gather insight as to whether the tailoring of marketing and advertisement efforts to the prescribed determinants are effective. By comparing the findings of this research study with the result from the loyalty assessment, it can be desired customer 
responses, which can foster customer loyalty. This study can serve as a contribution to hotel-related managers or hotel owners/investors. As mentioned, the ability to foster customer loyalty can, thereby, ensure a steady stream of revenue to the hotel. To assist in achieving this endeavor, the assessment of customer loyalty, it will be advantageous for hotel owners/investors and hotel-related managers to collaborate in efforts to brainstorm and construct strategic efforts that could be necessary.

\section{Acknowledgement}

This research is partially supported by University Sains Malaysia research grant and fellowship sachem.

\section{References}

Antony, F., \& Ghosh, S. (2004): Evaluating service quality in a UK hotel chain: a case study, International Journal of Contemporary Hospitality Management, 16(6): 380-384.

Baloglu, S. (2002). Dimensions of customer loyalty: Separating friends from well -wishers. Cornell Hotel and Restaurant Administration Quarterly, 43(1): 47-60.

Bojanic, D. (1996). Consumer perceptions of price, value, and satisfaction in the hotel industry: An exploratory study. Journal of Hospitality \& Leisure Marketing, 4(1): 5-23

Brady, M.K. \& Cronin, J.J. Jr. (2001): Customer orientation: effects on customer service, Journal of Service marketing, 3(3): 241-51.

Gold, M. (2005): What inspires loyalty? [Electronic Version]. Caterer \& Hotelkeeper, 195(4395)

Hair, Jr., J. F., Anderson, R. E., Tatham, R. L., \& Black, W. C. (1984): Multivariate Data Analysis: with Readings (4th ed. 1995). Prentice-Hall, Englewood Cliffs, NJ

Lal, R. \& Bell, D. (2003): The impact of frequent shopper programs in grocery retailing, Quantitative marketing and economics, 1: 179-202.

Lau, P. M., Akbar, A. K., \& Fie, D. Y. G. (2005): Service quality: A study of the luxury hotel in Malaysia, Journal of American Academy of Business, Cambridge, 7(2): 46-55

McCain, S., Jang, S., \& Hu, C. (2005): Service quality gaps analysis toward customer loyalty: practical guidelines for casino hotels. International Journal of Hospitality Management, 24(3): 465-472

Malaysian Association of Hotels, (2004): Tsunami Disaster: Report from Malaysian Association of Hotels.

Skogland, I. \& Siguaw, J. 2004): Are your satisfied customers loyal? Cornell Hotel and Restaurant Administration Quarterly, 45(3), 221-235.

Suh, S. (1997): The impact of consumer involvement on the consumers' perception of service quality focusing on the Korean hotel industry, Journal of Travel and Tourism Marketing, 6(2): 3

Taylor, S., Celuch, K., and Goodwin, S. (2004): The importance of brand equity to customer loyalty, Journal of Product \& Brand Management, 13(4): 217-227.

Teare, R. \& Bowen, J. (1997): Assessing information needs and external change, International Journal of Contemporary Hospitality Management, 9(7), 274-284.

White, S. S. \& Schneider, B. (2000). Climbing the commitment ladder: the role of expectations disconfirmation in customers' behavioral intention, Journal of Science Research, 2(3): 240-53 